\title{
Detecting wakefulness
}

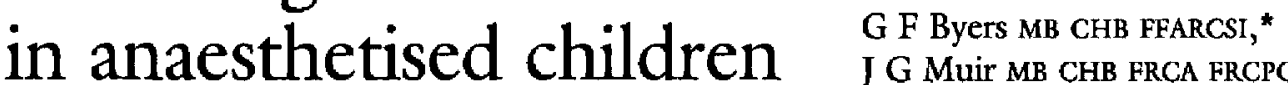

Purpose: To investigate the suitability of the isolated forearm technique in detecting wakefulness in children aged 5 to 16 yr.

Methods: Forty-one healthy English speaking children were enrolled. Following intravenous induction of anaesthesia with $5-7 \mathrm{mg} \cdot \mathrm{kg}^{-1}$ thiopentone $\mathrm{i}$, but before administration of $1-1.5 \mathrm{mg} \cdot \mathrm{kg}^{-1}$ succinylcholine a pneumatic tourniquet was inflated to $50 \mathrm{mmHg}$ above systolic pressure in order to isolate the non-cannulated forearm. Thereafter, anaesthesia was maintained with halothane 1.5-2.5\% in nitrous oxide and oxygen. Following the muscle relaxant the patient was instructed to move the unparalyzed arm. Movement was checked at 30 sec intervals and if present on command, identified as wakefulness.

Results: Movement of the isolated forearm to command was observed in $19.5 \%$ of children. The youngest child to respond was five years old.

Conclusion: The isolated forearm technique can be used to detect wakefulness during and immediately following tracheal intubation in children from the age of five years.

Objectif : Déterminer si la technique de l'avant-bras isolé est capable de déceler l'état de veille chez des enfants agés de 5 à 16 ans.

Méthodes : Quarante et un enfants anglophones participaient à cette étude. Après l'induction de l'anesthésie avec 5-7 mg. $\mathrm{kg}^{-1}$ de thiopentone $\dot{w}_{1}$ mais avant l'administration de $1-1,5 \mathrm{mg} \cdot \mathrm{kg}^{-1}$ de succinylcholine, un garrot pneumatique était insufflé à $50 \mathrm{mmHg}$ au-dessus de la pression artérielle systolique pour isoler le membre supérieur libre de toute canulation. Par la suite, l'anesthésie était maintenue avec de l'halothane 1,5-2,5\% dans le protoxyde d'azote avec oxygène. Après l'administration du relaxant musculaire, on demandait au patient de bouger son bras non paralysé. Le mouvement était vérifié à des intervalles de $30 \mathrm{sec}$ et s'il apparaissait sur commande, il était considéré comme une manifestation de l'état de veille.

Résultats : Un mouvement de l'avant-bras isolé a été observé chez 19,5\% des enfants. Le plus jeune à répondre avait cinq ans.

Conclusion : La technique de l'avant-bras isolé peut détecter l'état de veille pendant et immédiatement après l'intubation de la trachée chez des enfants à partir de l'àge de cinq ans.

\footnotetext{
From the Department of Paediatric Anaesthesia, Izaak Walton Killam-Grace Health Centre for Children, Women \& Families, P.O. Box 3070, 5850 University Avenue, Halifax, Nova Scotia B3T $3 G 9$.

"Present Address: Department of Anaesthesia, Aberdeen Royal Infirmary, Foresterhill, Aberdeen, Scorland.

Address correspondence to: Dr. John G. Muit, Phone: 902-428-8251; Fax: 902-428 8826; E-mail: jgmuirهis.dal.ca

Accepted for publication February 17, 1997.
} 
W

HEN defining awareness during operation, Wilson stated that a patient is considered aware if some incident related to the procedure, and which may or may not have been painful, is remembered. ${ }^{1} \mathrm{He}$ suggested that the definition may be extended to include dreaming and perhaps amnesic wakefulness. Using the isolated forearm technique, Tunstall defined amnesic wakefulness as being awake but having no post-operative recall. ${ }^{2}$ The isolated forearm technique involves placing a pneumatic tourniquet on the arm and inflating it above systolic pressure after administration of an induction agent, but before administration of muscle relaxants. The patient is then instructed to move the isolated arm. Such movement to command is interpreted as wakefulness. Studies using this technique have been carried out in adults, ${ }^{2,3}$ but there are no references to its use in children. Studies of awareness in children have relied on post operative questioning and have used per-operative dreaming as an indicator of awareness. In a study of 202 children aged 7-11 yr, McKie and Thorp reported an $11 \%$ incidence of dreaming and a $5 \%$ incidence of recall. ${ }^{4}$ Hobbs $e t$ al., studied 120 children aged 5-17 years found a $19 \%$ incidence of dreaming, but no recall. $^{5}$

\section{Methods}

Approval was obtained from the Hospital Ethics Committee and written informed consent was obtained from parents or guardians. Forty-one ASA grade I or II children whose first language was English were studied. Children were excluded if there was a history or signs of mental impairment, neuromyopathic disorders or other impediments to a positive response to the movement command. The children were informed that they would be asked to move their hand when they were "asleep" for their operation, and it was checked that they could obey a simple command similar but not identical to that used intra-operatively. All were unpremedicated and were either day cases or same day admissions for adenoidectomy.

Following insertion of an iv cannula, an automatic pneumatic tourniquet was placed on the arm opposite to that of the cannula. Following administration of 5$7 \mathrm{mg} \cdot \mathrm{kg}^{-1}$ thiopentone and after loss of the eyelash reflex but before the administration of $1-1.5 \mathrm{mg} \cdot \mathrm{kg}^{-1}$ succinylcholine, it was inflated to a pressure of 50 $\mathrm{mmHg}$ above systolic blood pressure. The patient's lungs were then inflated with oxygen $100 \%$ and the trachea was intubated once the anaesthetist was satisfied with the relaxation. Following intubation, anaesthesia was continued with nitrous oxide, oxygen and halothane $2 \%$ and spontaneous breathing was allowed to resume. The halothane concentration was increased to $2.5 \%$ if the patient moved the isolated forearm on command. It was reduced to $1.5 \%$ if the patient was bradycardic or hypotensive.

After inflation of the tourniquet, the patient was asked to squeeze the investigator's (GB) hand at $30 \mathrm{sec}$ intervals and any movement of the isolated limb was noted. Movement to command was doubly checked by asking the patient to squeeze the investigator's hand, and then relax and repeat the squeeze. The tourniquet remained inflated and the instructions to move the isolated arm continued until spontaneous ventilation resumed. Surgery was not allowed to commence until it was ensured that the patient was no longer moving the limb. The tourniquet was always removed before the commencement of surgery. Movement was defined as none, to command, or random. Random movement was movement of the isolated arm which was not in response to command or did not obey the command (i.e., flexion or extension movements of arm rather than gripping movements of the hand).

Anaesthesia was maintained with halothane $1.5-2.5 \%$ in nitrous oxide $66 \%$ and oxygen $33 \%$ with spontaneous respiration. Following completion of surgery $1 \mathrm{mg} \cdot \mathrm{kg}^{-1}$ meperidine $i m$ was administered.

All children were interviewed before discharge from the recovery ward using a standard questionnaire ${ }^{4}$ incorporated into a conversation. Specifically, each child was asked if they remembered anything after going to sleep and also about per-operative dreaming.

\section{Results}

The patients' demographic data are detailed in Table I. Eight of 41 children (19.5\%) moved the isolated arm to command (Table II). Movement to command

TABLE I Patient demographics

\begin{tabular}{ll}
\hline Patients - n: $(\mathrm{M} / \mathrm{F})$ & $41(22 / 19)$ \\
Age - yr: mean (range) & $11.1(5-16)$ \\
Weight - kg: mean (range) & $40.9(15-82)$ \\
\hline
\end{tabular}

TABLE II Patient movement

\begin{tabular}{llll}
\hline Movement & None & Random & To Command \\
\hline $\begin{array}{c}\text { Patients - } \mathrm{n}: \\
\quad(\mathrm{M} / \mathrm{F})\end{array}$ & $3(1 / 2)$ & $30(16 / 14)$ & $8(5 / 3)$ \\
$\begin{array}{c}\text { Age - yr: } \\
\text { mean (range) }\end{array}$ & $12.3(10-14)$ & $9.0(5-15)$ & $10.5(5-15)$ \\
$\begin{array}{c}\text { Weight - kg: } \\
\text { mean (range) }\end{array}$ & $48.1(40.6-61)$ & $38.3(15-82)$ & $40.1(20-62)$ \\
\hline
\end{tabular}


occurred in four patients at $30 \mathrm{sec}$, before tracheal intubation. In the other four it commenced between one and three minutes after intubation. All patients who moved to command had ceased movement by five minutes from induction.

Dreaming was reported by three of the 41 patients, but only one of these also moved the isolated arm to command. No patient had any recall for intra-operative events.

\section{Discussion}

Although no patient in this study had any recall for intra-operative events, eight of 41 patients moved to command and thus must be labeled as wakeful. The use of muscle relaxants and other drugs abolish respiratory pattern, movement and tone as signs of anaesthetic depth, while pupillary and eye reflex signs become less reliable. ${ }^{6,7}$ These signs can only serve as a guide for assessing anaesthetic depth.

Awareness at the time of intubation has been reported previously, and it was suggested that this may be due to redistribution of the induction agent while the relaxant is still active. ${ }^{8}$ Hobbs et al., have suggested that succinylcholine causes cerebral arousal and therefore may be actively implicated as a cause of dreaming. ${ }^{5}$

Thiopentone $5-7 \mathrm{mg} \cdot \mathrm{kg}^{-1}$ is recommended for induction of anaesthesia in children. ${ }^{9}$ It can be seen from the results that there is an incidence of wakefulness in unpremedicated patients receiving this dose of thiopentone followed by succinylcholine. Other factors should be considered when choosing the induction dose of thiopentone, but from this study it can be seen that 5-7 $\mathrm{mg} \cdot \mathrm{kg}^{-1}$ may be inadequate to prevent awareness, especially in unpremedicated children.

In this study, three (7.3\%) patients reported dreaming. This compared with 19\% (23 of 120) found by Hobbs $e t a l$., in paralysed and ventilated patients, ${ }^{5}$ and $11 \%$ (22 out of 202) found by McKie and Thorp. ${ }^{4}$ In McKie and Thorp's study, five patients who reported dreaming were anaesthetised by a spontaneous ventilation technique. Wakefulness was more prevalent than dreaming; only one patient displayed both.

The isolated forearm technique gives rise to a variety of movement in the isolated arm, not to command, but in response to stimuli such as intubation. This has previously been reported by Wilson. ${ }^{3}$ This movement may be a response to pain and suggests that the patients are not in a plane of surgical anaesthesia but this has not been shown to equate with awareness. We defined wakefulness as movement to command and non purposeful movement was disregarded.
Thornton et al., compared the isolated forearm technique with audio evoked responses in adults. ${ }^{10}$ They found a correlation between the audio evoked response pattern seen in patients who moved the isolated arm to command, and those who were lightly anaesthetised. They suggested that the isolated forearm technique underestimates the incidence of light anaesthesia. Millar and Watkinson found no correlation between the isolated forearm technique and the EEG response. ${ }^{11}$ However their patients were premedicated, and they commented that this may have some bearing on the findings.

It must be noted that all our patients were unpremedicated and were all same day admissions or day-cases. Our results show that standard doses of thiopentone (5-7 mg. $\mathrm{kg}^{-1}$ ) may not ensure absence of awareness. There is a need for a further larger study to determine this.

We have shown that the isolated forearm technique can be used to detect wakefulness in children over five years old. It is an easy test to apply using normal apparatus and interpretation of results is straightforward.

\section{References}

1 Wilson ME. Awareness under anaesthesia (Editorial). Anaesthesia 1982; 37: 263-5.

2 Tunstall $M E$. Detecting wakefulness during general anaesthesia for Caesarian section. BMJ 1977; 1: 1321.

3 Wilson ME. Detection of wakefulness during general anaesthesia (Letter). Br J Anaesth 1981; 53: 1234.

4 McKie $B D$, Thorp EA. Awareness and dreaming during anaesthesia in a paediatric hospital. Anaesth Intensive Care 1973; 1: 407-14.

5 Hobbs AJ, Bush GH, Downham DY. Peri-operative dreaming and awareness in children. Anaesthesia 1988; 43: 560-2.

6 Guedel $A E$. Inhalation Anesthesia. A Fundamental Guide, 2nd ed. New York: The Macmillan Co., 1952.

7 Gillespie NA. The signs of anaesthesia. Anesth Analg 1943; 22: 275-82.

8 McKenna J, Wilton TNP. Awareness during endotracheal intubation. Anaesthesia 1973; 28: 599-602.

9 Epstein BS, Hannallab RS. Outpatient anesthesia. In: Gregory GA (Ed.). Pediatric Anesthesia, 2nd ed. New York: Churchill Livingstone, 1983: 729-63.

10 Thornton C, Barrowcliffe MP, Konieczko KM, et al. The auditory evoked response as an indicator of awareness. Br J Anaesth 1989; 63: 113 5.

11 Millar K, Watkinson N. Recognition of words presented during general anaesthesia. Ergonomics 1983; 26: 585-94. 